\title{
Studying Adolescent Male Sexuality: Where Are We?
}

\author{
Laureen H. Smith, ${ }^{1}$ Barbara J. Guthrie, ${ }^{2}$ and Deborah J. Oakley ${ }^{3}$
}

Received February 10, 2004; revised July 19, 2004; accepted August 16, 2004

This article critically reviews the literature about adolescent males' sexuality in order to describe the state of the science and to identify promising concepts and research designs that have the potential to guide the next generation of research. A critique was conducted on 94 peer-reviewed studies of sexual behaviors that included a sample of adolescent males; 11 scholarly texts and 2 dissertations. Most studies lacked a theoretical foundation and had cross-sectional designs. For those studies with a theoretical base, 3 perspectives were most often used to guide research: cognitive, biological, or social-environmental. Studies frequently relied on older adolescents or young adult males to report behaviors during early adolescence. Male-only samples were infrequent. Findings include (a) the measurement of sexual activity is frequently limited to coitus and does not explore other forms of "sex"; (b) cognitive factors have been limited to knowledge, attitudes, and intent; (c) little is known about younger males based on their own self-reports; (d) little is known about the normative sexuality development of gay adolescent males; and (e) longitudinal studies did not take into account the complexities of biological, social, and emotional development in interaction with other influences. Research on adolescent sexuality generally is about sexual activity, with little research that includes cognitive competency or young males' sense of self as a sexual being. The purpose of the paper is to critically review the literature about male sexuality in order to describe the state of the science as well as to identify potential directions to guide the next generation of adolescent male sexual being research.

KEY WORDS: male adolescent; sexuality; sexual activity; adolescence; sexual being; sexual behavior.

${ }^{1}$ Assistant Professor in the School of Nursing at Oakland University. Received her PhD in Nursing from the University of Michigan, with a specialization in Health Promotion and Risk Reduction. Research interests include adolescent health behaviors, male sexuality, and fostering youth through community-based, asset-building interventions. To whom all correspondence should be addressed at the School of Nursing, Oakland University, 458 O'Dowd Hall, Rochester, Michigan, 48309; e-mail: lhsmith@oakland.edu.

${ }^{2}$ Associate Professor and Director for Undergraduate \& Non Traditional Programs in the School of Nursing at the University of Michigan. Inducted as a Fellow in the Academy of American Nurses. Received a PhD in Nursing from New York University. Research interests include female adolescent health and health-compromising behaviors, specifically the influence of contextual environments on adolescents' participation in health promoting or health-compromising behaviors.

${ }^{3}$ Professor Emeritus in the School of Nursing and Center for Nursing Research at the University of Michigan. Received a PhD in Public Health from the University of Michigan. Research interests include women's and men's contraceptive use behaviors, development of nursing in China, and health policy.

\section{INTRODUCTION}

Adolescent males are rarely the focus of research related to adolescent sexuality or sexual activity. The focus of most studies has been females and their sexual activity (Jadack and Keller, 1998; Kalmuss et al., 2003; Kirby, 1999; Miller and Moore, 1990). While male sexual activity increasingly [more often] is being included in peer-reviewed studies, the exclusive focus on understanding male sexual activity is less common despite differences in the antecedents or predictors of sexual activity by gender (DeGaston et al., 1996; Dittus et al., 1997; Forste and Haas, 2002; Kalmuss et al., 2003; Miller et al., 1998; Small and Luster, 1994). For example, genders frequently differ in sexual values and attitudes (Carvajal et al., 1999). Males generally hold more permissive sexual values and are more accepting of premarital coitus than females (Carvajal et al., 1999; DeGaston et al., 1996). Second, the genders differ in their personal views of sexual 
activity and its relation to the self. Males are more accepting or willing to have sexual intercourse and view coitus as a positive part of the self, compared to female peers (Martin, 1996; Rucibwa et al., 2003; Small and Luster, 1994). Third, males and females may differ in the relative effect of intrapersonal, interpersonal and extra-personal factors (Boyce-Rogers, 1999; Forste and Haas, 2002). Adolescent males also are more influenced by external factors, compared to their female peers (Boyce-Rogers, 1999).

The male perspective increasingly is recognized as being different from their female counterparts. Given this recognition, male sexual activity is increasingly being included in studies on adolescent sexual activity (Coker et al., 1994; Day, 1992; DeGaston et al., 1996; Forste and Haas, 2002). Yet, studies focusing on males are few and generally a-theoretical; as a result, male sexuality remains somewhat poorly understood (Brindis et al., 1998; Gates and Sonenstein, 2000; Kalmuss et al., 2003; Rucibwa et al., 2003).

Greater understanding of gender-specific factors is necessary to develop effective and efficient programs targeting adolescent males. To improve our understanding about the state of the science of this area of research, the growing but disparate body of literature was reviewed. This review is limited to documented studies in peerreviewed journals, scholarly textbooks, and dissertations published between 1965 and 2003. The aim of the review is not just to describe and summarize this literature, but also to identify the next steps to expand the scientific knowledge base by building on this body of research.

\section{METHODS}

A total of 94 studies were selected using the standard computer indexing services of Medline, Cinal, Psychlit, and Pro-Quest. Keywords of male sexuality, sexual being, adolescent sexual behavior, adolescent sexual activity, and male sexual behaviors were entered into the search engine of the databases. When entered alone, adolescent male sexuality and sexual being generated few matches so the search was expanded to include sexual activity and sexual behaviors. Articles had to include a sample of adolescent males between the ages of 9 and 19 or, if a retrospective design, be focused on the adolescent period. Articles were published in specialty journals, disciplinary journals, and interdisciplinary journals. Eleven scholarly textbooks and 2 dissertations also were reviewed and critiqued.

As shown in Table I, more than $3 / 4$ of the studies and all of the texts were published since 1990 . The earlier studies included were seminal studies that were founda- tional to the later studies. Adolescent male sample sizes ranged from 20 to more than 1,500. More than $38 \%$ of the studies had sample sizes of 500 or more. While the majority of studies were cross-sectional, $42 \%$ had longitudinal designs. Only $16 \%$ of the studies had male-only samples. Two-thirds were a-theoretical, and the remainder were based on 3 theoretical assumptions - biological, social-environmental, and cognitive. One-fourth did not provide data on the age distribution, but few included the extreme ends of the adolescent age spectrum, and specifically younger adolescents. Only 1 in 10 included measures of oral and/or anal sex along with vaginal intercourse.

\section{RESULTS}

Most studies focusing on adolescent sexual activity were limited by a monolithic view of sexual activity that has the potential to limit the understanding needed to develop a scientific basis for interventions (Capaldi et al., 1996; Chapin, 2000; Jadack and Keller, 1998; Kirby, 1999, 2002). For example, to a large extent, these studies viewed sexual activity as heterosexual coitus rather than including other precoital activities such as kissing, fondling and petting, or other forms of sexual activity such as group activities, oral sex or anal sex (Blum et al., 2000; BoyceRogers, 1999; Crockett et al., 2003; Ensminger, 1990; Ford et al., 1994). Although more recent studies also have continued to promote the persistence of the monolithic view of heterosexual activity, oral and anal sex now is sometimes noted (Ellen et al., 2002; Gates and Sonenstein, 2000; Halpern, 2000).

Lacking from these studies is the inclusion of genderspecific factors that shape sexual activity, such as the notion of sexual being (Brooks-Gunn and Graber, 1999; Kalmuss et al., 2003; Miller, 1999). However, most of the studies identified (Chapin, 2000; Jadack and Keller, 1998; Kirby, 1999) focused solely on sexual activity rather than the broader context of one's sexual being. For the purpose of this paper, sexual being is defined as the cognitive generalizations about sexual aspects of the self that is the manifestation of past experiences used to shape and guide current sexual behavioral activities (Anderson et al., 1999). Sexual being is socially constructed, situational, influenced, and given meaning by its location in time and social space (Stein, 1989). Sexual being provides sexual subjectivity, and shapes and guides sexual activity.

The greatest amount of research on sexual activity and sexuality has been a-theoretically driven, defined here as lacking an explicit or implicit theoretical perspective (Abernathy et al., 1979; Dittus and Jaccard, 2000; Halpern et al., 2000; Jadack and Keller, 1998; Miller 
Table I. Characteristics of Reviewed Studies $(N=95)$

\begin{tabular}{lrclrr}
\hline \multicolumn{1}{c}{ Years published } & $N$ & Percentage & Study designs & $N$ & Percentage \\
\hline $1960 \mathrm{~s}$ & 1 & 1.1 & Cross-sectional & 54 & 56.8 \\
$1970 \mathrm{~s}$ & 1 & 1.1 & Longitudinal & 40 & 42.1 \\
$1980 \mathrm{~s}$ & 13 & 13.7 & Qualitative & 1 & 1.1 \\
$1990 \mathrm{~s}$ & 52 & 54.7 & & & \\
$2000 \mathrm{~s}$ & 27 & 28.4 & & & \\
Sample size & $N$ & Percentage includes & Ages (years) & $N$ & Percentage \\
Not reported & 15 & 16.0 & Not reported & 20 & 21.1 \\
$<100$ & 12 & 12.8 & $<10$ & 3 & 3.1 \\
$100-250$ & 19 & 20.2 & $10-13$ & 23 & 24.2 \\
$251-500$ & 12 & 12.8 & $14-17$ & 37 & 38.9 \\
$501-999$ & 15 & 16.0 & $18+$ & 12 & 12.6 \\
$1000+$ & 21 & 22.3 & & & \\
Male-only & 16 & 16.8 & & & \\
Sexual activity measures & $N$ & Percentage & & & \\
Coitus-only & 63 & 70.0 & & & \\
Precoital and coitus & 18 & 20.0 & & & \\
Oral, anal contact included & 9 & 10.0 & & & \\
\hline
\end{tabular}

and Moore, 1990). More than half $(n=54)$ of the reviewed studies lacked a theoretical perspective, including studies published in more recent years. Other studies (Boyce-Rogers, 1999; Day, 1992; Forste and Haas, 2002; Whitaker et al., 2000) also lacked an explicit theoretical perspective. Therefore, the reader is left to assume the theoretical perspective guiding the study, which may be erroneous or problematic. For those studies that were guided by theory, certain patterns emerged (Hovell et al., 1994; Miller and Moore, 1990; Miller et al., 2000; Udry, 2000).

As shown in Table II, 3 primary theoretical perspectives were invoked most often to explain adolescent sexual activity. The first perspective viewed sexuality as a biological unfolding or emergence and the second perspective viewed sexuality as a socially shaped and environmentally learned behavior (Miller, 1999; Miller et al., 1987; Tollman and Diamond, 2000). The third perspective viewed sexuality as a sense of self that guides sexual activity (Leventhal, 1993). These contrasting perspectives constitute the conceptual foundations for much of the research on adolescent sexuality (Miller, 1999; Tollman and Diamond, 2000). All 3 perspectives demonstrate some usefulness for understanding adolescent male sexual activity. Even when studies or models included aspects from all perspectives, most studies focused primarily on either the biological, social or cognitive perspective. Current theoretical understanding recognizes the importance of all 3 perspectives, but the relative importance of the biological, social, or cognitive influences remains unclear. Recent theoretical work appears to promote the maturational and cognitive development of the adolescent that is embedded in the social construction of adolescent sexual activity, which differs for each gender (Bearman and Bruckner, 2001; Carvajal et al., 1999; Smith, 1997). Table II summarizes the findings from the reviewed studies according to biological, social constructive, and cognitive variables common to several studies.

Each perspective provides uniquely different views of sexuality and, in particular, male sexuality. Biological studies (Udry, 1988; Udry and Billy, 1987) were used in early studies of male sexual activity. These focused on physical maturity, the hormonal influences on puberty, and pubertal development as factors predicting male sexual activity. Biological factors were found to be strong predictors of male sexual activity, specifically the initiation of coitus.

\section{Biological Explanations}

The physical changes of puberty are defining features of adolescence that are profound and visible to the self, parents, peers, and others (Florsheim, 2003). Consequently, pubertal maturity and age often are studied as factors related to age of first coitus. Motivation for sexual activity has been conceptualized as being determined by biological motivation prompted by pubertal development and hormones such as testosterone (Graber and Bastiani, 2001; Spencer et al., 2002; Udry, 1988). A biological explanation for sexual activity may be more important for males, compared to female peers (Udry and Billy, 1987). For example, sexual activity for males may be 
Table II. Significant Findings from Studies with Biological, Social-Environmental, or Cognitive Explanations

\begin{tabular}{|c|c|}
\hline Variable & Author(s) and year of publication \\
\hline Age & $\begin{array}{l}\text { Biological explanations } \\
\text { Coker } \text { et al. } \text { (1994), Hovell et al. }(1994), \text { Mott } \\
\text { et al. }(1996), \text { Upchurch et al. }(1999), \text { Gates } \\
\text { and Sonenstein (2000), Aten et al. }(2002), \\
\text { Forste and Haas (2002) }\end{array}$ \\
\hline Race and age & $\begin{array}{l}\text { Ku et al. (1998), Sonenstein et al. (1998) [98], } \\
\text { Santelli et al. (2000) [96], Kaplan et al. } \\
\quad \text { (2001) [97], Aten } \text { et al. (2002) }\end{array}$ \\
\hline Pubertal maturity & $\begin{array}{l}\text { Udry and Billy (1987), Udry (1988), Halpern } \\
\text { et al. (1993), Miller et al. (1998), Spencer } \\
\text { et al. (2002) }\end{array}$ \\
\hline Hormones (testosterone) & $\begin{array}{l}\text { Udry (1988), Udry and Billy (1987), Udry and } \\
\quad \text { Billy (1987), Halpern et al. (1993) }\end{array}$ \\
\hline
\end{tabular}

Sexual minority

Deviancy/delinquency

Substance use

Family structure and function

Parental values and attitudes
Kurdek (1994), Savin-Williams (1996), Peplau et al. (1997), Kurdek (1998), Savin-Williams (1998), Diamond (2003)

Social-environmental explanation Rosenbaum and Kandell (1990), Ensminger (1990), Small and Luster (1994), Social Forces (1994), Coker et al. (1994), Kowaleski-Jones and Mott (1998), Halpern et al. (2000), Aten et al. (2002) Santelli et al. (1998), Kowaleski-Jones and Mott (1998)

Udry and Billy (1987), Miller et al. (1987), Rosenbaum and Kandell (1990), Flewelling and Bauman (1990), Day (1992), Social Forces (1994), Hovell et al. (1994), Tubman et al. (1996a, b), Mott et al. (1996), Smith (1997), Dittus et al. (1997), Upchurch et al. (1998), Raine et al. (1999), Huerto-Franco and Malacara (1999), Upchurch et al. (1999), Bearman and Bruckner (2001), Davis and Friel (2001), Rucibwa et al. (2003)

Newcomber and Udry (1985), Moore et al. (1986), Hovell et al. (1994), Small and Luster (1994), Smith (1997), Whitbeck (1999), Dittus and Jaccard (2000), Sieving et al. (2000), Zall-Crawford (2001)
Tubman et al. (1996a,b), Porter et al. (1996),
Increasing age is associated with an increased likelihood of coitus. Most males initiate coitus by age 18

Rates of reported coitus increased for all males age 15-19 from 1978 to 1988 but has diminished for Caucasian and African-American males in recent years. Rates of reported coitus has remained constant for Hispanic males in recent years

The more physically mature male is at greater risk for initiating coitus compared to less physically mature males (regardless of age)

Pubertal timing is an unrelated covariate to the timing of first coitus (Spencer et al.)

Motivation to engage in coitus may be prompted by testosterone which may be more important for males, compared to female peers (Udry; Udry and Billy)

Testosterone's effect on sexual activity may be indirect [working through physical maturity] (Halpern et al.)

Nearly $10 \%$ of males will engage in "homosexual" sexual behaviors at some point in their lives (Diamond)

Most gay males report the recognition of "gay feelings" during adolescence

Gay adolescent males report higher rates of depression and victimization, compared to heterosexual peers

There is an association between coitus and other risk behaviors

Males may engage in no other delinquent behaviors and still engage in sexual activity (Ensminger et al., Small and Luster)

The strongest association for males is between alcohol or marijuana use and coitus (males who use these substances are more sexually experienced, compared to non-users)

Family structure appears to be least understood for males in predicting sexual activity, especially for African-American, males

Residing with both biological parents may be protective against the initiation of early coitus for younger males, but the effect of residing with a biological father is least understood for African-American males

Residing with a sibling who was a teenage parent may influence Hispanic males to engage in coitus (Rucibwa et al.)

Adolescent males whose parents have more permissive sexual attitudes/values are more likely to initiate coitus at earlier ages and to have more lifetime sexual partners, especially for younger males 
Table II. Continued

Family strengths and transitions

Parent control and monitoring

Family communication

Friends/peers

School/academics

School environment
Dorius et al. (1993), Capaldi et al. (1996), Heights and Werner-Wilson (1998)

Newcomber and Udry (1985), Udry and Billy (1987), Ensminger (1990), Hovell et al. (1994), Romer et al. (1999), Capaldi et al. (1996), Smith (1997), Miller et al. (1998), Heights and Werner-Wilson (1998), Kirby (1999), Whitbeck (1999), Upchurch et al. (1999), Miller et al. (2000), Dittus and Jaccard (2000), Forste and Haas (2002), Hollander (2003)

Moore et al. (1986), Miller and Moore (1990), Darling and Hicks (1982), Coker et al. (1994), DeGaston et al. (1996), Dittus et al. (1997), Heights and Werner-Wilson (1998), Miller et al. (1998), Boyce-Rogers (1999), Diiorio et al. (1999), Kirby (1999), Romer et al. (1999), Miller et al. (2000), Romo et al. (2002)

Green (1985), Newcomb et al. (1986), Feldman et al. (1995), DeGaston et al. (1996), Heights and Werner-Wilson (1998), Lerner and Galambos (1998), Jadack and Keller (1998), Diiorio et al. (1999), Rice (1999), Whitbeck (1999), Miller et al. (2000), Bearman and Bruckner (2001), Cooksey et al. (2002), Rucibwa et al. (2003)

Dorius et al. (1993), Small and Luster (1994), Coker et al. (1994), Capaldi et al. (1996), Tubman et al. (1996a,b), Stouthamer-Loeber and Wei (1998), Whitbeck (1999), Fortse and Haas (2002)

Furstenberg et al. (1987), Rosenbaum and Kandell (1990)
Perceived parental opposition to sexual initiation may decrease as the adolescent male ages (Whitbeck, Dittus and Jaccard)

Male adolescents are more likely to underestimate parental disapproval of coitus if they perceive parental approval of birth control use, have initiated coitus, and report parental behaviors typical of less control

If divorce, death or repartnering of parents occurs during a boys adolescence, the boy may be at increased risk to initiate coitus

Monitoring activities seems to be effective in delaying sexual activity for younger males

Males are generally monitored less, have fewer dating rules, and are less compliant with established rules, compared to female peers

Boys who perceive their parents as over-controlling may be more likely to initiate coitus at earlier ages (Upchurch and Aneshensel, Forste and Haas)

Family communication has no significant impact on sexual activity or at best has mixed results, especially for males

Many males report less parental communication, compared to female peers

Parent-son discussions generally occur sporadically, infrequently, and often after the son has already initiated coitus

Males generally receive more prosexual messages, compared to females

Adolescent males are more comfortable discussing sexual issues with friends, rather than their families

Adolescent males who discuss sexual issues with friends rather than their families may be more likely to engage in coitus

Normative peer pressures influence adolescent male sexual behavior, values and attitudes

Younger adolescent males are more likely to submit to peer pressure, compared to female counterparts and older males

Adolescent males have more desire for sexual intimacy during the initial phase of a dating relationship, compared to females, but this difference diminishes as the relationship develops when the desire for intimacy equalizes (Jadack and Keller)

Males tend to report more casual relationships with first sexual partners, compared to females (Cooksey et al.)

Academic performance may not be a significant predictor of adolescent male sexual activity, but may be significant for females (Tubman et al., Whitbeck et al.)

Achieving high grades in school decreases the odds of first sex (Forste and Haas)

The school environment may be an important factor, especially for African-American males (Furstenberg et al.) 
Table II. Continued

Neighborhood/community

Race/ethnicity

Socio-economics

Media

Victimization

Sexual values and attitudes

Intention (to engage in coitus)

Self-esteem
Duncan (1995), Lerner and Galambos (1998), Upchurch et al. (1999)

Ford et al. (1994), Porter et al. (1996), Smith (1997), Miller et al. (1998), Murphy and Boggess (1998), Ku et al. (1998), Sonenstein et al. (1998), Upchurch et al. (1999), Carvajal et al. (1999), Huerto-Franco and Malacara (1999), Santelli et al. (2000), Bearman and Bruckner (2001)

Ensminger (1990), Dittus et al. (1997),

Kowaleski-Jones and Mott (1998), Diiorio et al. (1999), Romer et al. (1999), Gates and Sonenstein (2000), Miller et al. (2000), Aten et al. (2002), Forste and Haas (2002)

Arnett (1995), Huston et al. (1998), Kaiser Family Foundation (1999), Dreisbach (2000), Chapin (2000), Remez (2000)

Poitras and Lavoie (1995), Kaiser Family Foundation (1999), Capaldi and Gorman-Smith (2003)

Cognitive explanations

DeGaston et al. (1996), Jadack and Keller (1998), Heights and Werner-Wilson (1998), Miller et al. (1998), Diiorio et al. (1999), Carvajal et al. (1999)

Oliver and Hyde (1993), Stanton et al. (1996), Ku et al. (1998), Bearman and Bruckner (2001)

Miller et al. (1987), Kowaleski-Jones and Mott (1998), Whitbeck (1999), Spencer et al. (2002)
African-American males who attended predominately Caucasian schools initiated coitus at a later age, compared to the peers who attended predominately African-American schools (Rosenbaum et al.)

Growing up in poor neighborhoods with a lack of opportunity is related to teen childbearing, higher abortion rates, and lower marriage rates (Duncan)

Boys who perceive their neighborhood as unsafe have significantly higher rates of first coitus, compared to boys living in safer neighborhoods (Upchurch and Aneshensel)

Age of first coitus is clearly related to race with African-American adolescent males more likely to report younger ages of first coitus compared to Caucasian, Asian-American, and Hispanic males

Although the gap between the races is diminishing for males, African-American males continues to initiate sex at the earliest ages

Caucasian males progress to coitus in a more predictive manner with more precoital activities, whereas African-American males progress to coitus more quickly with less precoital activity

Research has often focused on urban, low-income African-American populations

Males who reside in poorer neighborhoods are more likely to initiate coitus at earlier ages

Increasing family income raises the odds of sexual initiation for males at any age (Forste and Haas)

The number and explicitness of sexual messages have increased over time

Sexual behaviors are portrayed as recreational activities

Boys are generally the perpetrator in unwanted sexual contact (Poitras and Lavoie)

Aggressive boys are more likely to become men who engage in violent romantic relationships (Capaldi and Gorman-Smith)

Males generally have more permissive sexual values and are more accepting of coitus, compared to female peers

Sexual attitudes and values are generally less predictive of sexual activity for males, compared to females

The intention to abstain from future coitus is a stable predictor for actual behavior among virgins but less stable among those who are sexually experienced (Stanton et al., Bearman and Brucker)

Findings are less predictable for males, compared to female peers

Young males with higher levels of self-esteem engage in coitus earlier and more frequently (Kowaleski-Jones and Mott, Spencer et al.)

Other studies have found no effect 
Table II. Continued

\begin{tabular}{ccc}
\hline Variable & Author(s) and year of publication & Findings \\
\hline Sexual knowledge & $\begin{array}{c}\text { DiClemente } \text { et al. (1990), Walter } \text { et al. (1992), } \\
\text { Schuster } \text { et al. (1998), Jadack and Keller } \\
(1998), \text { Dreisbach (2000), Aarons } \text { et al. (2000) }\end{array}$ & $\begin{array}{c}\text { Sexual knowledge increases sexual self-efficacy, especially for } \\
\text { condom use in males (Schuster } \text { et al.) }\end{array}$ \\
& Sexual knowledge does not correlate with safer sexual practices \\
\hline
\end{tabular}

strongly influenced by hormones, i.e., androgens (Udry and Billy, 1987). In contrast, females are less likely to be affected by hormones and more influenced by social controls (Udry and Billy, 1987). Since few, if any, recent biological studies have included large, ethnically diverse samples of males, the reported pubertal and coital findings must be viewed with caution, especially for groups within groups (e.g., Hispanic males with differing national origins and generations; African-Americans with differing family incomes and/or neighborhoods).

Halpern et al., found that pubertal development was a statistically significant predictor of sexual activity and that testosterone's effect was indirect [working through pubertal development] (1993). Testosterone by itself was not found to be significantly related to the likelihood of having coitus (Halpern et al., 1993). This longitudinal panel study was an improvement over the design of previous cross-sectional work conducted by Udry, but relied on single hormone measures and did not study the impact of ethnicity on hormonal shifts, even though different ethnic groups seem to mature at different rates, with African-American adolescents maturing at the earliest ages, compared to Caucasians, Hispanics, and AsianAmericans (Rice, 1999). Furthermore, in a sample of 1214-year-old males followed over a 2-year period, Spencer et al. (2002) found pubertal timing to be unrelated to the initiation of coitus.

The relative importance of biological indicators, specifically hormonal influences, and the mediating versus moderating effect of these indicators remains somewhat misunderstood, especially for males. Biology is accepted as an important factor in understanding adolescent sexual activity; however, the role that biology plays compared to the developmental expectations associated with one's age or maturity is less clear. The role of visible physical development versus hormonal influences on sexual intentions, sexual activity, and socially expected behavior remains poorly understood with inconsistent findings (Halpern et al., 1993; Udry, 1988). The question remains: To what extent does physical maturation, spurred by hormonal changes, predict one's sexual activity, enhance sexual identity, or result in society promoting or encouraging physically mature males to engage in sexual activity?
Sexual-Minority (Homosexual) Males

The emergence of male masculinity during adolescence is viewed as natural since the visible attributes of masculinity are triggered by hormones and biology. Subsequently, teenage males are expected to act masculine and participate in heterosexual dating (Martin, 1996). More recently, research on homosexual adolescents has increased but such research has focused disproportionate attention to risk behaviors, victimization, and depression. The normative developmental factors of homosexual identity and sexuality have been studied far less frequently (Diamond, 2003). Additionally, most studies focusing on the dynamics of homosexual romantic relationships have relied on adult populations rather than adolescents (Kurdek, 1994, 1998; Peplau et al., 1997). Recognizing the importance of romantic relationships for the developmental transitions of youth and the formation of one's sexuality, researchers are now beginning to explore the formation of romantic relationships and expression of masculinity in adolescent homosexual males; however, much remains to be learned (Savin-Williams, 1996, 1998). As a result of the noted limitations found in the biological perspective, many researchers have turned to the social construction perspective.

\section{Social-Environmental Explanations}

Most studies citing a theoretical foundation use a social construction perspective (Hovell et al., 1994; Lerner and Galambos, 1998; Miller et al., 2000; Smith, 1997). From the social construction perspective, family, peer, school, and media factors are among the most explored variables with a general consensus that these factors are associated with adolescent male sexual activity (Feldman et al., 1995; Forste and Haas, 2002; Green, 1985; Hovell et al., 1994; Kirby, 1999, 2002; Lerner and Galambos, 1998; Newcomb et al., 1986; Rucibwa et al., 2003). The social construction perspective groups factors into one of two levels of influence-proximal or distal factors. Proximal factors are more closely tied to the person and include intrapersonal factors such as sexual attitudes and some 
interpersonal factors such as one's family. Distal factors such as one's ethnicity, neighborhood and socioeconomic status are indirectly connected to a person but still have an impact. The social-environmental explanations include Social Control and Strain Theories, ecological perspectives, and motivational theories.

\section{Social Control and Strain Theories}

Social Control and Strain Theories are a form of social construction theories that are classed as social disorganization models. Social disorganization models assert that the causes of deviance reside in the community's inability to realize the common values of its residents (Bursik, 1988; Sampson, 1992; Social Forces, 1994), and assume a basic normative consensus in society regarding values or the desirability of coitus among adolescents (Social Forces, 1994). Social disorganization models look for explanations of deviance in the relative lack of articulation of values between culture and social structure (Kornhauser, 1978; Social Forces, 1994). Adolescent sexual activity is viewed as a risk behavior and as such, sexual activity is frequently studied with other risk behaviors.

In these models, although related to risk behaviors, the perceived deviancy of sexual activity is implied but may differ by gender. For example, the potential costs or benefits of an action, specifically sexual activity, varies according to one's gender. Females may perceive more potential or actual costs for engaging in sexual activity, such as the risk of pregnancy and its resultant consequences. On the other hand, males may perceive more benefits associated with coitus, which is supported in society. Society generally values and accepts male sexual activity as a significant measure of maleness or masculinity (Forste and Haas, 2002; Kalmuss et al., 2003; Martin, 1996; Rucibwa et al., 2003). Consequently, when compared with female sexual activity, male sexual activity may not be perceived as a deviant act. Because social disorganization models fail to make this gender-specific distinction, these lack usefulness in explanation, specifically for males (Social Forces, 1994).

Teenagers who participate in delinquent behaviors of alcohol and marijuana use are at increased risk for engaging in sexual activity (Kowaleski-Jones and Mott, 1998; Santelli et al., 1998; Tubman et al., 1996a,b). Other delinquent behaviors such as truancy, assault, smoking, and weapon use generally are not associated with adolescent male coitus but have been associated with the number of sexual partners reported by males (Valois et al., 1997, 1999). In addition, males who have not engaged in other risky behaviors or acts of delinquency still may be sex- ually active (Ensminger, 1990; Small and Luster, 1994). The temporal ordering of risk behaviors is not clear. For example, do teenagers engage in sexual activity when they are under the influence of mind-altering drugs, or do they experiment with sexual activity after experimenting with other risky behaviors? Because most of the studies utilized cross-sectional designs, causality cannot be assumed.

\section{Ecological Perspectives}

In recent years, researchers have given more weight to the contributions of family and everyday surroundings to adolescents' social construction of self. Particular aspects of adolescent ecology that may be associated with male sexual being include broader contextual factors such as one's school, neighborhood, economic situation, and the media, as well as more proximate factors such as family, peers, and behavioral characteristics (Duncan, 1995; Forste and Haas, 2002; Kirby, 2002; Lerner and Galambos, 1998; Small and Luster, 1994). Behavior, including sexual activity, is influenced by these intrapersonal, interpersonal, and extrapersonal factors that are likely to interact. These multiple levels of interaction are relevant for understanding human behavior, including sexual activity (Sallis and Owen, 1997). Families have been frequently studied as an influencer on adolescent behavior, including sexual activity.

Families are the first context in which adolescent boys are socialized into gender roles, including sexuality, masculinity, and ethnicity (Harter, 1999). Numerous studied have demonstrated that family and familial factors strongly influence adolescent sexual behavior and sexual activity. Family variables include family structure and family functioning (Bearman and Bruckner, 2001; Davis and Friel, 2001; Hovell et al., 1994; Huerto-Franco and Malacara, 1999; Miller et al., 1987; Rucibwa et al., 2003; Upchurch et al., 1999).

Although extensively studied, family structure appears to be least understood for adolescent males (Davis and Friel, 2001; Mott et al., 1996; Rucibwa et al., 2003; Smith, 1997; Social Forces, 1994; Udry and Billy, 1987). The impact of family structure on adolescent males' sexual activity is not conclusive and may not be predictive of male sexual activity, especially for African-American males (Mott et al., 1996; Smith, 1997; Social Forces, 1994). Conversely, findings from numerous studies suggest that family functioning is essential to understanding adolescent male sexual activity. Various aspects of family functioning have been studied, including attitudes and values of parents toward adolescent sexuality (Dittus and Jaccard, 2000; Hovell et al., 1994; Sieving et al., 2000; 
Zall-Crawford, 2001), family strengths and transitions (Capaldi et al., 1996; Heights and Werner-Wilson, 1998), parental control and monitoring (Capaldi et al., 1996; Dittus and Jaccard, 2000; Ensminger, 1990; Forste and Haas, 2002; Rucibwa et al., 2003), and family communication (Boyce-Rogers, 1999; Coker et al., 1994; Darling and Hicks, 1982; DeGaston et al., 1996; Diiorio et al., 1999). In addition, parental values frequently are studied because they are thought to influence adolescent sexual activity.

Although findings appear to hold true for actual parental values as reported by parents and perceived parental values as reported by adolescents (Dittus and Jaccard, 2000; Miller et al., 2000), there are several limitations associated with parental values related to males' sexual activities. First, most studies included only mother or mother-figure parental measures even when the father or father-figure was available (Hovell et al., 1994; Miller et al., 2000; Moore et al., 1986; Newcomber and Udry, 1985). Further, fathers and mothers may not agree about sexual values and attitudes (Miller et al., 2000). Finally, parental values frequently are measured by asking the adolescent about these values (DeGaston et al., 1996; Rucibwa et al., 2003; Small and Luster, 1994). This is problematic given that several researchers (Dittus and Jaccard, 2000; Miller et al., 2000) have found a discord between adolescent perceptions of parental values and actual parental values. A final theme is that these studies assumed that parents held conservative values on adolescent coitus and thus would discourage such behavior in their offspring. This assumption may not hold true, especially for males. Males are socialized to engage in sexual activity as a part of their masculinity (Forste and Haas, 2002; Martin, 1996). Consequently, the opposite of what is assumed may hold for males, since adolescent males may actually be encouraged to engage in sexual activity.

Family transitions such as divorce, death and repartnering occur in many families, even among unmarried parents. If they occur during adolescence, boys may be at increased risk for initiating early coitus (Capaldi et al., 1996; Dorius et al., 1993). This effect may be mediated by parental dating behaviors that are copied by the adolescent (Capaldi et al., 1996).

Residing with both biological parents seems to be protective against early initiation of coitus for most boys (Day, 1992; Dittus et al., 1997; Flewelling and Bauman, 1990; Raine et al., 1999; Smith, 1997; Tubman et al., 1996a,b; Upchurch et al., 1998). Even so, the effect of residing with a biological father is least understood for African-American males. Some studies found that African-American males who resided with their biological fathers were more likely to engage in early coitus (Day, 1992; Rucibwa et al., 2003; Smith, 1997), while other studies found no interaction by race (Dittus et al., 1997). These inconsistent findings might be due in part to the paucity of developmental research in the area of AfricanAmerican males. Even less is known about Hispanic males from differing ethnic heritages. The impact of fathers, father-figures generally, and more specifically fathers of color is poorly understood and needs to be included in future studies (Mott et al., 1996; Rucibwa et al., 2003).

Parents often attempt to influence adolescent behavior through control and by monitoring activities such as homework, friendships, and social activities. Overall, males generally are monitored less frequently by parents, have fewer dating rules, and are less compliant with established rules than girls (Hovell et al., 1994; Romer et al., 1999). Additionally, parental control must be delicately balanced. Perhaps the fear of over-control leads many parents to establish fewer rules for boys, compared to their female peers.

Recent studies (Forste and Haas, 2002; Heights and Werner-Wilson, 1998; Hollander, 2003; Miller, 1999) have found that parental monitoring delays initiation of coitus by younger adolescent males, while earlier studies (Newcomber and Udry, 1985; Udry and Billy, 1987) found that parental interactions and monitoring had little effect on the current sexual behavior of males. The older studies, however, had several significant limitations, including cross-sectional designs, small sample sizes, an older mean age of the samples, and reliance on maternal influences. The strength of more recent studies is their longitudinal designs and use of larger samples. Many recent studies also have included younger males, compared to past studies.

Studies on family communication have found no significant impact or mixed results at best, especially for males (Boyce-Rogers, 1999; Darling and Hicks, 1982; DeGaston et al., 1996; Kirby, 1999; Miller et al., 1998; Romo et al., 2002; Romer et al., 1999). Many males reported less frequent parental communication, compared with females (Romer et al., 1999). Parent-son sexual discussions generally occurred sporadically and infrequently due to the sensitive nature that often leads parents to wait until after they suspected that their son was sexually active. Sexual messages delivered by parents also may differ for males and females (Darling and Hicks, 1982; Dittus et al., 1997). Males have been found to receive more sexual messages, compared with females (Darling and Hicks, 1982), with less stress on responsibility, consequences, and values for boys (Dittus et al., 1997; Romo et al., 2002).

Most studies included only maternal discussions (Miller et al., 2000; Romo et al., 2002). Father-son 
discussions generally were not included. Thus, a better understanding of paternal influences is needed (Miller and Moore, 1990). Do fathers encourage sons to engage in coitus as a transitional behavior into manhood? Do fathers want their sons to delay coitus, or is the father's message one of acceptance and encouragement to experience sexual activity?

Studies often relied on the child's reporting of parental communication (Boyce-Rogers, 1999; DeGaston et al., 1996; Miller, 1999; Moore et al., 1986). Reliance on adolescent recall is problematic because parents and children may not agree about the amount or content of sexual discussions held (Newcomber and Udry, 1985). Studies have argued that adolescent perception of parental communication is most important because that perception has an impact on decision-making and behavior. By not including parents, a vital source of data and information is lost. Furthermore, studies generally have not analyzed??[found?] any congruency between parent and child perceptions regarding communication. As a result, when parents are not included in such studies, the puzzle of parental communication remains unsolved.

Finally, most studies have relied on retrospective recall of parental communication, which introduces bias concerning the timing of discussions, frequency of discussions, and the content of discussions. Longitudinal studies are needed to measure parental communication as it occurs in the life-course and how it is or is not part of developmental transitional stages that may lead to the initiation and continuation of coitus.

A narrow view of family, specifically focusing on parent-child measures, limits the knowledge gained from research studies. Missing from most studies are inquiries into the effects of siblings and sibling relationships on teenage male sexual activity (Whitbeck, 1999). For example, siblings serve as both models and mentors for behaviors, including sexual activity. Particularly for teenage boys, older brothers may serve as the only male role model in matriarchal single parent structures.

In addition to family, extra-familial factors such as peers, school affiliation, ethnicity, and one's neighborhood influence adolescent males' sexual activity (Kirby, 2002; Lerner and Galambos, 1998; Upchurch et al., 1998). Especially for males, peers are an important social network that has an impact on adolescents and adolescent sexual activity. Peers provide adolescent males with support, mentoring, modeling, and a network for dating and dating behaviors. In addition, normative peer pressures among friends influence adolescent male behavior, values, and attitudes (Bearman and Bruckner, 2001; Cooksey et al., 2002; Kalmuss et al., 2003; Kirby, 2002; Lear, 1997; Lerner and Galambos, 1998; Rucibwa et al., 2003; Whitbeck, 1999). Through peer relationships and interactions, male teenagers seek to fulfill several developmental needs including physical, emotional, and sexual intimacy (Fiering and Furman, 2000). However, the temporal ordering of peer intimacy remains unknown. For example, whether teenagers choose friends who share similar sexual experiences, or whether they model the sexual activities of their friends remains unclear. The contextual and situational circumstances that influence teenage friendships and dating behaviors remain understudied (Cooksey et al., 2002; Kirby, 2002).

Not all sexual experiences are entirely voluntary, especially for younger adolescents (Kaiser Family Foundation, 1999). Boys generally are the perpetrators of unwanted sexual contact; however, studies generally have relied on self-report as a means of obtaining data (Poitras and Lavoie, 1995). Researchers have found links in the development of aggressive, antisocial boys over a long period of time. Capaldi and Gorman-Smith (2003) found that aggressive boys were likely to become men who engaged in violent romantic relationships. In turn, aggressive men tended to find partners who were aggressive thus continuing the cycle of abuse (Capaldi and Gorman-Smith, 2003).

The research on adolescent aggressive behaviors is plagued by many methodological issues. First, terms such as aggression, abuse, violence, and battering are used interchangeably; many studies focused only on acts of physical aggression (Capaldi and Gorman-Smith, 2003). A second limitation is related to sampling. The majority of studies have relied on convenience samples, especially school-based convenience samples (Capaldi and GormanSmith, 2003). Students who did not attend school or who were absent from school were not included, which may bias findings and lead to the underestimation of prevalence in youth populations.

In addition, racial and ethnic differences have been noted in reported sexual behaviors. Caucasian males have been found to progress to coitus in a more predictable manner, with more precoital behaviors, while AfricanAmerican males progressed to coitus more quickly and with fewer precoital behaviors (Forste and Haas, 2002; Ku et al., 1998; Miller and Moore, 1990; Murphy and Boggess, 1998; Smith and Udry, 1985). For AfricanAmerican males, no predictive progression in precoital activity may exist. The normative transition of Hispanic and Asian males is even less clear because they are least studied (Villarruel and Rodriguez, 2003).

Because most studies have focused on peer influences using mainly Caucasian samples, peer influences on African-American and Hispanic males' sexual activity remains poorly understood, resulting in the need to develop more racial/ethnic specific studies to fully understand and 
predict sexual activity (Ku et al., 1998; Miller et al., 1998; Mott et al., 1996; Villarruel and Rodriguez, 2003). These racial-specific models are especially needed for young African-American and Hispanic males since the sexual activity of this subgroup remains so poorly understood.

The influence of school and school affiliation increasingly is being recognized as a possible factor in understanding adolescent male sexual activity. The results are mixed, especially concerning academic performance and sexual activity. Some studies seem to indicate that academic performance is not a significant predictor of adolescent male sexual activity but may be significant for females (Tubman et al., 1996a,b; Whitbeck, 1999). However, another more recent study has found that academic performance is significant for males (Forste and Haas, 2002).

The temporal ordering of school performance or dropout and sexual activity also is not understood. Initiating sex may increase the odds of dropping out of school (Dorius et al., 1993), or dropping out of school may increase the odds of engaging in sexual activities. Most studies are unable to predict temporal ordering because of their cross-sectional, retrospective designs; therefore, more longitudinal studies are needed.

The environmental context of the school, specifically the racial composition, may be another important factor for African-American males (Furstenberg et al., 1987; Rosenbaum and Kandell, 1990). What remains unclear is how to differentiate the influence of the school context from school norms. Many studies focus solely on school performance but fail to fully explore the school context itself such as the sense of affiliation or connectedness to a school. Males involved in school activities and with a sense of affiliation to teachers may be more motivated to perform well, remain in the school, and develop educational aspirations beyond high school. Teachers also serve as mentors and role models as well as provide sexual knowledge. Consequently, males may delay sexual activity due to perceived risks and costs in the hopes of remaining in the school environment.

The community and neighborhood context also has been found to influence adolescent sexuality and sexual activity (Kirby, 2002; Lerner and Galambos, 1998). Among both African-American and Caucasian adolescents, living in a socially disorganized, low-income community is associated with the initiation of coitus (Hollander, 2003; Lerner and Galambos, 1998). Most adolescent males of color included in studies were from disadvantaged neighborhood settings. Consequently, findings regarding ethnic differences were only representative of disadvantaged males of color. Multiple, overlapping factors seem to function within the neighborhood or com- munity of boys that influence their behavior. The risk of becoming sexually active is not solely due to socioeconomic status or the ethnic composition of the neighborhood, but rather the social conditions that covary with these structural attributes (Kirby, 2002; Upchurch et al., 1999).

Additional studies are needed to further disentangle the multiple influences found within neighborhoods and communities. The disentanglement of factors such as ethnicity, income, and perceived safety is necessary in order to understand the relative influence of each factor and its relationship to the neighborhood and to adolescent sexual activity. Studies are needed that analyze neighborhood factors over time, rather than those that employ a cross-sectional design. Studies and models are needed that consider the relative impact of one's neighborhood compared to other factors such as ethnicity, family, and friends in order to fully understand the contexts that have the most powerful impact.

Ethnic group membership affords the individual a cultural identity that tends to influence how one views the world and fulfills gender roles, including sexual roles (Spencer, 1991). Ethnicity provides a richness and meaning to one's life, customs, and traditions. Ethnicity and ethnic differences frequently are measured using racial categories. While racial differences have been recognized for decades, African-American male sexual activity remains poorly understood. Findings generally are not useful for African-American males, compared to other gender and ethnic groups (Miller, 1999; Miller and Moore, 1990; Porter et al., 1996; Smith, 1997; Upchurch et al., 1999). Additionally, even though ethnic differences of male sexual activity have long been recognized, the meaning or causes of these ethnic differences are poorly understood. Studies of ethnic groups from varying socioeconomic and educational backgrounds are needed to further understand the true impact of ethnicity on adolescent male sexual activity.

Research often has focused on urban, low-income African-American adolescents. Indeed, many studies have investigated almost entirely African-American or other adolescent boys of color (Aten et al., 2002; Diiorio et al., 1999; Dittus et al., 1997; Ensminger, 1990; Forste and Haas, 2002; Gates and Sonenstein, 2000; Kowaleski-Jones and Mott, 1998; Miller et al., 2000; Romer et al., 1999). In doing so, non-urban AfricanAmericans and adolescents of other ethnic groups from both rural and urban settings remain understudied. Consequently, most studies cannot be generalized to other adolescent populations.

In the majority of studies, the effects of ethnicity simply are biproducts of statistical controls for ethnicity. As 
a result, the amount of variance contributed by ethnicity and race often reflects the researcher's strategy to reduce extraneous variance as much as possible (McLeroy et al., 1998). Second, ethnic/race comparisons generally are not guided by a theoretical or conceptual rationale needed for such comparisons (McLeroy et al., 1998). Finally, race and ethnicity are used as interchangeable concepts, neither of which is appropriately measured or analyzed. Furthermore, broader contextual variables are needed to measure whether it is race, ethnicity, culture, or contextual variables that influence sexual activity.

Today's teenagers spend several hours a day either watching television, playing video games, listening to music, or surfing the Internet (Dreisbach, 2000). Consequently, the majority of youth are processing multiple media messages about sexuality, sexual behavior, and sexual risks and basing sexual decision-making in part on these messages (Kaiser Family Foundation, 1999). Studies that have tracked sexual content in television, movies, music, and videos agree that the number and explicitness of sexual references have dramatically increased over the years and that sexual behavior is portrayed as a recreational activity with an emphasis on physical attraction (Huston et al., 1998; Remez, 2000).

More research is needed to gauge the impact of various media messages. Media outlets may differ in their relative impact on adolescents. Visual versus vocal images may not be equal in their relative impact or influence. Male adolescent realities may differ from female adolescent and adult perceptions. For example, just because adults worry about how the media portrays sexuality does not mean that adolescents perceive that same content as sexual or that males may perceive the content differently than their female peers (Huston et al., 1998; Remez, 2000). Furthermore, the media may be imitating the reality of teenagers' lives rather than determining that reality (Arnett, 1995). Although the interaction between youth and the media is well accepted, greater understanding is needed.

\section{Cognitive Explanations}

Motivational theories frequently are employed in the study of adolescent sexual activity and sexually related behaviors. Factors often studied include the cognitive variables of motivation, normative values and attitudes, self-efficacy, and future intentions of behavior. Models including these factors have been successfully employed in health promoting projects aimed at decreasing adolescent sexual activity and/or promoting condom use during sexual activity (Carvajal et al., 1999; Tschann $e t$ al., 2002).
Several studies have suggested that the different normative transitions to coitus between Caucasian and African-American males may be the result of different motivations to engage in coitus. For example, Ford et al. (1994) and Cookey et al. (2002) found that ethnic differences were greatest for males reporting of "casual partners" with African-American males reporting significantly more "casual partners," compared to Caucasian males. Males, especially African-American males, may engage in sexual activity to combat loneliness or for physical pleasure, compared to females whose different motivations include intimacy, commitment, and connectedness (Bearman and Bruckner, 2001; Huerto-Franco and Malacara, 1999). Missing from these studies is mention of Hispanic males' normative transition to coitus, thus creating a gap in knowledge and understanding about this subpopulation of adolescent males of color. Motivational theories recognize the importance of social and cultural factors and conceptualize determinants as proximal and distal (Hovell et al., 1994). One proximal factor frequently studied is one's sexual values and attitudes.

Religiosity has been studied as both a proxy measure and a separate factor influencing sexual values. Although there are an abundance of studies on the influence of religion on sexuality, most of these studies have focused primarily on females and sampled from conservative subgroups. Compared with their female peers, males generally are less religious. Additionally, both religiosity and sexual values have been found to be less predictive of male sexual activity, compared to females (Udry and Billy, 1987). Cognitive researchers (Leventhal, 1993) recognize these as part of a young person's developing sense of self that we have termed one's sexual being.

Sexual values, sexual attitudes, sexual intention, and self-efficacy are frequently studied variables as predictors of adolescent sexual activity. Researchers and theorists often speculate that adolescent males and females differ in their attitudes and values about sexuality and in their actual sexual activity (Jadack and Keller, 1998). Findings are less predictable for males (Miller et al., 1998). The role of intention in sexual activity also seems to be influenced by whether an adolescent is a virgin. Recent studies also have shown that today's adolescents are more accepting of premarital coitus, compared to previous generations of adolescents, and that gender differences found in adolescents decrease with increasing age (Ku et al., 1998; Oliver and Hyde, 1993). The majority of cognitive studies however have focused mainly on females; therefore, one is left unsure of their relevance for males.

The relative impact and temporal ordering of the role of sexual value in sexual activity is less clear. For example, one cannot ascertain if sexual values direct subsequent 
behavior or if one's behavior influences the resulting sexual values. A young person's sexual experiences can alter their resulting sexual attitudes (Kowaleski-Jones and Mott, 1998). One's sexual values and attitudes also have been found to influence sexual activity (DeGaston $e t$ al., 1996; Diiorio et al., 1999; Kirby, 2002). The normative context that religiosity and sexual values hold for adolescents and their personal cultures needs to be further understood.

Self-esteem may impact males and females differently when predicting sexual activity. Kowaleski-Jones and Mott (1998) and Spencer et al. (2002) have found that young males with higher levels of self-esteem have been found to engage in coitus earlier and more frequently, as opposed to females who engage in early coitus when displaying lower levels of self-esteem. Other studies have not reported any gender differences in the effect of selfesteem on initiation of sexual activity (Forste and Haas, 2002; Miller et al., 1987; Whitbeck, 1999). Like most studies, these more recent studies are limited by their cross-sectional, retrospective designs and sample selection that excludes younger high-risk males.

Adolescents receive sexual knowledge from a variety of sources with some knowledge being accurate and some knowledge being inaccurate or conflictual (Dreisbach, 2000). Teenagers learn sexual "facts" and cultural values from traditional sources such as family, school, and church. Conflicting information, knowledge, and values are learned from the media and peers. Personal experiences and observations also contribute to knowledge and values (Dreisbach, 2000). Most research on male sexual knowledge has focused on formalized sexual knowledge obtained through school and family settings and whether this formal knowledge influences subsequent sexual behaviors (Jadack and Keller, 1998).

Sexual knowledge has been found to increase sexual self-efficacy, particularly concerning condom use (Schuster et al., 1998). In contrast with what may be expected, knowledge about the transmission of sexually transmitted infections is not correlated with safer sex practices including abstinence (Jadack and Keller, 1998). Many researchers have demonstrated that male adolescents with high levels of formal sexual knowledge continue to have sex and practice unsafe sex (DiClemente et al., 1990; Walter et al., 1992). What remains unclear is what role more informal sources of sexual knowledge such as the media, peers, and personal experiences or observations may have on sexual practices.

In summary, although the biological, social environmental, and cognitive perspectives have provided insight into the understanding of sexual decision-making and sexual activity in males, these perspectives have not been extensively examined for the ways in which they shape young males' sense of self as a sexual being. Since this sense is developmentally malleable, especially during the early years of adolescence, knowing more about the growth of the sense of self as a sexual being may lead to more effective interventions.

\section{FUTURE DIRECTIONS}

New directions are needed in future research on adolescent sexual activity. Little is known about males, especially those younger than 15 years (Jadack and Keller, 1998; Oliver and Hyde, 1993). Most studies to date of adolescent behavior have been in older teenagers or young adults and relied on quantitative research designs (Oliver and Hyde, 1993). There are few prospective studies of teenage males prior to their becoming sexually active, and still fewer studies exploring adolescent male sexuality that are grounded in qualitative methods (Remez, 2000).

Second, adolescents are embedded in social contexts such as one's culture, school, family, peers, and romantic relationships that interact with individual factors and which, in turn, determine adolescent behavior including sexual activity. Little is known about the contexts or circumstances in which sex takes place (Kirby, 2002; Miller and Moore, 1990; Norris and Ford, 1999; Schuster et al., 1998). For example, power, sexual self-efficacy, and decision-making within the varying relational contexts are generally not studied (Ford et al., 2001; Tschann et al., 2002).

Consensual coitus is rarely distinguished from forced sex (Whitbeck, 1999). What remains unclear is the context within adolescent dating relationships that contributes to coercive sexual contact such as the meaning, motivation, and consequence of this violence (Florsheim, 2003). Clearer conceptualization and methodological definition of the types of aggression would advance the field of study. In addition, more is known about the influence of peers and family on sexual behaviors than of romantic partners (Florsheim, 2003). In addition, what teens consider to be "sex" varies by contextual and situational factors such as who was doing what to whom and whether it leads to orgasm (Remez, 2000). Further work is needed to clarify the circumstances under which sex is initiated and continued.

Third, a narrow view of family, specifically focusing on parent-child measures, limits the knowledge gained from previous research studies. Missing from most studies are inquiries into the effects of grandparents, proxy parents, siblings, and sibling relationships on teenage 
male sexual activity (Whitbeck, 1999). For example, siblings serve as both models and mentors for behaviors, including sexual activity (Rucibwa et al., 2003). Especially for teenage males, older brothers may serve as the only male role model within matriarchal single parent family structures.

Fourth, adolescent males of color residing in middle class neighborhoods with parents who complete post-high school education are not clearly understood. Many adolescent males of color included in studies are from disadvantaged neighborhood settings. Consequently, findings regarding ethnic differences are only representative of disadvantaged adolescent males of color. Further study of ethnic groups from varying socioeconomic and educational backgrounds is needed to further understand race or ethnicity's true impact on adolescent male sexual activity.

Fifth, research on the normative developmental features of sexuality in sexual-minority youth is needed. The dynamics of homosexual and bisexual adult romantic relationships have received most research attention to date (Diamond, 2003). In order to adequately address the relational and developmental concerns of sexual-minority adolescent males, the full range of variation of sexual and affectional desires for the same sex must be more fully understood, especially for adolescent males.

Finally, studies that focus on sexual being or other broader contextual views of adolescent sexuality are lacking (Kalmuss et al., 2003; Kirby, 2002). The internal sexual states that shape and guide sexual experiences are not understood, especially for adolescent males. Sexual activity results from one's sense of sexual being but has been the sole focus of most research studies. A narrow view that focuses only on adolescent's sexual activity does not yield a holistic view of adolescent sexuality. Studies are needed that expand the concept of sexual activity to include sexual being and its impact on adolescent male sexual activity. Qualitative research approaches could bridge the gap between current knowledge and needed directions in the exploration of adolescent male sexuality.

In the holistic view of male sexual being, it is important to consider the ordering of developmental tasks, such as sexuality before intimacy verses intimacy before sexual activity (Chapin, 2000). To fully understand adolescent male sexual activity, the more internalized sense of one's sexual sense of being must be studied. How one moves from closeness to another and intimacy to the act of coitus, or whether coitus is even related to intimacy, remains poorly understood. Sexual being provides the missing piece of the puzzle, since sexual being guides and shapes sexual activity. Sexual being is a relatively new area of study; therefore, models that are theoretically driven are needed to guide research. These models need to incorporate both biological and social factors as possible predictors of not only male sexual activity but of sexual being as well.

Limitations for many studies that focus on adolescent male sexual activity and sexuality include the reliance on cross-sectional and prospective designs. These limitations could be addressed in future research by using longitudinal and qualitative designs. The study of younger adolescent males over time as their sense of sexual being evolves could generate rich data and information that can direct future interventions and programming targeting this population.

\section{CONCLUSIONS}

Adolescence is the period within the lifespan when most of a person's biological, cognitive, psychologi$\mathrm{cal}$, and social characteristics are changing from what is considered child-like to what is considered adult-like (Florsheim, 2003; Lerner and Galambos, 1998). It is a period of continual change and transition between individuals and their contexts (Lerner and Galambos, 1998). Research must be conducted with an appreciation of the individual differences in adolescent development that arise as a consequence of diverse families, peer influences, communities, and socio-cultural contexts. These diverse contexts interact to influence adolescents and their sense of themselves as a sexual being. One of the most challenging developmental tasks of teenagers is exploring and becoming comfortable with their sexuality and those behaviors and characteristics that define a person as sexual (Dreisbach, 2000). Although sexuality is an intrinsic aspect of human development physical, psychological, cognitive, and social changes related to sexuality are particularly prominent during the adolescent years (Dreisbach, 2000).

Since the majority of adolescents in the Western culture engage in sexual activity during the teenage years, this activity is not a delinquent act but rather a part of the normal developmental transition from childhood to adulthood. During adolescence, intimacy and establishing interpersonal relationships beyond the family is an accepted and expected task (Cooksey et al., 2002; Feldman and Elliott, 1997; Rice, 1999). Logically, sexual activity can and does become a part of this intimacy. Rather than view sexual activity as part of the other risk behaviors, a developmental perspective continues to be needed in future studies. This perspective posits sexual intimacy as an expected task of the adolescent period. Due to its normalcy, sexual activity simply cannot be grouped together with other risky behaviors. Although it may be classified 
as a risky behavior, sexual behaviors are different from other risk behaviors because of its prevalence and place in the normal development of beings.

An understanding of male adolescent sexuality requires a broader perspective. Much of the existing research on adolescent sexuality has focused on heterosexual youth from a predominant Western cultural perspective [or, view]. However, as much as $10 \%$ of male teenagers may consider themselves gay or bisexual at some point in their lives (Florsheim, 2003). The average age for first awareness of these feelings is approximately 13 for gay males (Remafedi, 1987). During the teenage years, the majority of these males engage in heterosexual dating (SavinWilliams, 1996). These sexual orientation patterns are not fully understood.

Finally, the increasing diversity of the United States population requires further research on dating patterns, cultural sexual practices, and sexual gender roles of teenage males from other cultures. Findings from studies including predominately Western heterosexual males cannot be applied or assumed for males who identify with other cultures. In addition, the exploration of sexual victimization and abuse within the cultural context is especially needed. Although much as been learned about adolescent sexuality and sexual behaviors over the past several decades, much work remains as research moves into new and exciting directions.

\section{REFERENCES}

Aarons, S., Jenkins, R., Raine, T., El-Khorazaty, M., Nabil, M. et al. (2000). Postponing sexual intercourse among urban junior high school students: A randomized, controlled evaluation. J. Adolesc. Health 27: 236-247.

Abernathy, T., Robinson, I., Balswick, J., and King, K. (1979). A comparison of sexual attitudes and behavior in rural, suburban, and urban adolescents. Adolescence 14: 289-295.

Anderson, B., Cyranowski, J., and Espindle, D. (1999). Men's sexual self-schema. J. Pers. Soc. Psychol. 76: 645-661.

Arnett, J. (1995). Adolescents' use of media for self-socialization. J. Youth Adolesc. 25: 519-534.

Aten, M., Siegel, D., Enaharo, M., and Auinger, P. (2002). Keeping middle school students abstinent: Outcomes of a primary prevention intervention. J. Adolesc. Health 31(1): 70-78.

Bearman, P., and Bruckner, H. (2001). Promising the future: Virginity pledges and first intercourse. Am. J. Sociol. 106: 859-912.

Blum, R., Beuhring, T., Shew, M., Bearinger, L., Sieving, R., and Resnick, M. (2000). The effects of race/ethnicity, income, and family structure on adolescent risk behaviors. Am. J. Public Health 90: 1879-1884.

Boyce-Rogers, K. (1999). Parenting processes related to sexual risk-taking behaviors of adolescent males and females. J. Marriage Fam. 61: 99-110.

Brindis, C., Boggess, J., Katsuranis, F., Mantell, M., McCarter, V., and Wolfe, A. (1998). A profile of the adolescent male family planning client. Fam. Plann. Perspect. 30: 63-66, 88.

Brooks-Gunn, J., and Graber, J. (1999). What's sex go to do with it? The development of sexual identities during adolescence. In Contrada,
R., and Ashmore, R. (eds.), Self, Social Identity and Physical Health: Interdisciplinary Explorations. Oxford Press, London.

Bursik, R. (1988). Social disorganization and theories of crime and delinquency: Problems and prospects. Criminology 26: 519-552.

Capaldi, D., Crosby, L., and Stoolmiller, M. (1996). Predicting the timing of first sexual intercourse for at-risk adolescent males. Child Dev. 67: 344-359.

Capaldi, D., and Gorman-Smith, D. (2003). The development of aggression in young male/female couples. In Florsheim, P. (ed.), Adolescent Romantic Relations and Sexual Behavior: Theory, Research and Practical Implications. Lawrence Erlbaum, London.

Carvajal, S., Parcel, G., Basen-Engquist, K., Banspach, S., Coyle, K., Kirby, D., and Chan, W. (1999). Psychological predictors of delay of first sexual intercourse by adolescents. Health Psychol. 18: $443-452$.

Chapin, J. (2000). Adolescent sex and mass media: A developmental approach. Adolescence 35: 799-811.

Coker, A., Richter, D., Valois, R., McKeown, R., Garrison, C., and Vincent, M. (1994). Correlates and consequences of early initiation of sexual intercourse. J. Sch. Health 64: 372-377.

Cooksey, E., Mott, F., and Neubauer, S. (2002). Friendships and early relationships: Links to sexual initiation among American adolescents born to young mothers. Perspect. Sex. Reprod. Health 34: 118-125.

Crockett, L., Raffelli, M., and Moilanen, K. (2003). Adolescent sexuality: Behavior and meaning. In Adams, G., and Berzonsky, M. (eds.), Blackwell Handbook of Adolescence. Blackwell, Malden, MA, pp. 371-392.

Darling, C., and Hicks, M. (1982). Parental influence on adolescent sexuality: Implications for parents as educators. J. Youth Adolesc. 11: 231-245.

Davis, E., and Friel, L. (2001). Adolescent sexuality: Disentangling the effects of family structure and family context. J. Marriage Fam. 63: 669-681.

Day, R. (1992). The transition to first intercourse among racially and culturally diverse youth. J. Marriage Fam. 54: 749-762.

DeGaston, J., Weed, S., and Jensen, L. (1996). Understanding gender differences in adolescent sexuality. Adolescence 31: 217-231.

Diamond, L. (2003). Love matters: Romantic relationships among sexual-minority youth. In Florsheim, L. (ed.), Adolescent Romantic Relations and Sexual Behavior: Theory, Research, and Practical Implications. Lawrence Erlbaum, London.

DiClemente, F., Forrest, K., Mickler, S., and Principal Site Investigators. (1990). College students' knowledge and attitudes about AIDS and changes in HIV-preventive behaviors. AIDS Educ. Prevent. 2: 201-212.

Diiorio, C., Kelley, M., and Hockenberry-Eaton, M. (1999). Communication about sexual issues: Mothers, fathers, and friends. J. Adolesc. Health 24: 181-189.

Dittus, P., Jaccard, J., and Gordon, V. (1997). The impact of African American fathers on adolescent sexual behavior. J. Youth Adolesc. 8: $1-10$.

Dittus, P., and Jaccard, J. (2000). Adolescents' perceptions of maternal disapproval of sex: Relationship to sexual outcomes. J. Adolesc. Health 26: 268-278.

Dorius, G., Heaton, T., and Steffen, P. (1993). Adolescent life events and their association with the onset of sexual intercourse. Youth Soc. 25: 3-23.

Dreisbach, S. (2000). Adolescent Sexuality: The Gap Between Knowledge and Action. University of Colorado, Denver.

Duncan, G. (1995). How non-marital childbearing is affected by neighborhoods, marital opportunities, and labor market conditions. In Moore, K. (ed.), Report to Congress on Out of Wedlock Childbearing. U.S. Department of Health \& Human Services, Hyattsville, MD.

Ellen, J., Adler, N., Gurvey, J., and Tschann, J. (2002). Adolescent condom use and perceptions of risk for sexually transmitted diseases. Sex. Transm. Dis. 29(12): 756-762.

Ensminger, M. (1990). Sexual activity and problem behaviors among black, urban adolescents. Child Dev. 61: 2032-2046. 
Feldman, S., and Elliott, G. (1997). At the threshold: The developing adolescent. Harvard, Cambridge, MA.

Feldman, S., Rosenthal, D., Brown, N., and Canning, R. (1995). Predicting sexual experience in adolescent boys from peer rejection and acceptance during childhood. J. Res. Adolesc. 5: 387-411.

Fiering, C., and Furman, W. (2000). When love is just a four letter word: Victimization and romantic relationships in adolescence. Child Maltreat. 5: 293-298.

Flewelling, R., and Bauman, K. (1990). Family structure as a predictor of initial substance use and sexual intercourse in early adolescence. J. Marriage Fam. 52: 171-181.

Florsheim, L. (2003). Adolescent Romantic Relations and Sexual Behavior: Theory, Research, and Practical Implications. Lawrence Erlbaum, London.

Ford, K., Rubinstein, S., and Norris, A. (1994). Sexual behavior and condom use among urban, low-income, African-American and Hispanic youth. AIDS Educ. Prevent. 6: 219-229.

Ford, K., Sohn, W., and Lepkowski, J. (2001). Characteristics of adolescents' sexual partners and their association with use of condoms and other contraceptive methods. Fam. Plann. Perspect. 33: 100-105, 132.

Forste, R., and Haas, D. (2002). The transition of adolescent males to first sexual intercourse: Anticipated or delayed? Perspect. Sex. Reprod. Health 34: 184-190.

Furstenberg, F., Morgan, S., Moore, K., and Peterson, J. (1987). Race differences in the timing of adolescent intercourse. Am. Sociol. Rev. 52: 511-518.

Gates, G., and Sonenstein, F. (2000). Heterosexual genital sexual activity among adolescent males: 1988 and 1995. Fam. Plann. Perspect. 32: 295-304.

Graber, J., and Bastiani, A. (2001). Psychosocial change at puberty and beyond: Understanding adolescent sexuality and sexual orientation. In Augelli, A., and Patterson, G. (eds.), Lesbian, Gay and Bi-Sexual Identities and Youth: Psychological Perspectives. Oxford Press, London.

Green, V. (1985). Experiential factors in childhood and adolescent behavior: Family interaction and previous sexual experiences. J. Sex. Res. 21: 157-182.

Halpern, C. (2000). Adolescent males' willingness to report masturbation. J. Sex. Res. 37: 327-332.

Halpern, C. (2003). Biological influences on adolescent romantic sexual behavior. In Florsheim, L. (ed.), Adolescent Romantic Relations and Sexual Behavior: Theory, Research and Practical Implications. Lawrence Erlbaum, London.

Halpern, C., Joyner, K., Udry, J. R., and Succindran, C. (2000). Smart teens don't have sex (or kiss much either). J. Adolesc. Health 26: 213-225.

Halpern, C., Udry, J. R., Campbell, B., and Succindran, C. (1993). Testosterone and pubertal development as predictors of sexual activity: A panel analysis of adolescent males. Psychosom. Med. 55: 436-447.

Harter, S. (1999). The construction of the self: A developmental perspective. Guilford Press, New York.

Heights, R., and Werner-Wilson, R. (1998). Gender differences in adolescent sexual attitudes: The influence of individual and family factors. Adolescence 33: 519-531.

Hollander, D. (2003). Teenagers with the least adult supervision engage in the most sexual activity. Perspect. Sex. Reprod. Health 35: 106.

Hovell, M., Sipan, C., Blumberg, E., Atkins, C., Hofstetter, and Kreitner, S. (1994). Family influences on Latino and Anglo adolescent's sexual behavior. J. Marriage Fam. 56: 973-986.

Huerto-Franco, R., and Malacara, J. (1999). Factors associated with the sexual experiences of underprivileged Mexican adolescents. Adolescence 34: 389-401.

Huston, A. C., Wartella, E., and Donnerstein, E. (1998). Measuring the Effects of Sexual Content in the Media. Kaiser Family Foundation, Menlo Park, CA.

Jadack, R., and Keller, M. (1998). Health Promotion Across the Lifespan. Mosby, Philadelphia, PA.
Kaiser Family Foundation. (1999). Kids and Media@the New Millennium: A Comprehensive National Analysis of Children's Media Use. Author, Menlo Park, CA.

Kalmuss, D., Davidson, A., Cohall, A., Laraque, D., and Cassell, C. (2003). Preventing sexual risk behaviors and pregnancy among teenagers: Linking research and programs. Perspect. Sex. Reprod. Health 35(7): 87-93.

Kaplan, D., Feinstein, R., Fisher, M., and Klein, J. (2001). Condom use by adolescents. Pediatrics 107: 1463-1469.

Kirby, D. (1999). Reflections on two decades of research on teen sexual behavior and pregnancy. J. Sch. Health 69: 89-94.

Kirby, D. (2002). Antecedents of adolescent initiation of sex, contraceptive use, and pregnancy. Am. J. Health Behav. 26: 473-485.

Kornhauser, R. (1978). Social Sources of Delinquency: An Appraisal of Analytic Models. University of Chicago Press, Chicago, IL.

Kowaleski-Jones, L., and Mott, F. (1998). Sex, contraception and childbearing among high-risk youth: Do different factors influence males and females? Fam. Plann. Perspect. 30: 163-168.

Ku, L., Sonenstein, F., Lindberg, L., Bradner, C., Boggess, S., and Pleck, J. (1998). Understanding changes in sexual activity among young metropolitan men: 1979-1995. Fam. Plann. Perspect. 30: 256262.

Kurdek, L. A. (1994). The nature and correlates of relationship quality in gay, lesbian, and hetero-sexual cohabitating couples: A test of the individual differences, interdependence, and discrepancy models. In Greene, B., and Herek, G. M. (eds.), Lesbian and Gay Psychology. Sage, Thousand Oaks, CA, pp. 133-155.

Kurdek, L. A. (1998). Relationship outcomes and their predictors: Longitudinal evidence from heterosexual married, gay, cohabitating, and lesbian cohabitating couples. J. Marriage Fam. 60: 553-568.

Lear, D. (1997). Sex and Sexuality: Risk and Relationships in the Age of AIDS. Sage, London.

Lerner, R., and Galambos. (1998). Adolescent development: Challenges and opportunities for research, programs, and policies. Annи. Rev. Psychol. 49: 413-446.

Leventhal, H. (1993). Theories of compliance and turning necessities into preferences: Application to adolescent health action. In Krasnegor, N. A., Epstein, L., Bennett-Johnson, S. et al. (eds.), Developmental Aspects of Health Compliance Behavior. Lawrence Erlbaum, Hillsdale, NJ, pp. 91-124.

Martin, K. (1996). Puberty, Sexuality and the Self: Girls and Boys at Adolescence. Routledge, New York.

McLeroy, K., Bibeau, D., and Steckler, A. (1998). An ecological perspective on health promotion programs. Health Educ. Q. 4: 351-377.

Miller, B., Christensen, R., and Olsen, T. (1987). Adolescent self-esteem in relation to sexual attitudes and behavior. Youth Soc. 19: 93-111.

Miller, B., and Moore, K. (1990). Adolescent sexual behavior, pregnancy, and parenting: Research through the 1980s. J. Marriage Fam. 52: 1025-1044.

Miller, B., Norton, M., Fan, X., and Christopherson, C. (1998). Pubertal development, parental communication, and sexual values in relation to adolescent sexual behaviors. J. Early Adolesc. 2: 1-10.

Miller, K. (1999). Adolescent sexual behavior in two ethnic minority samples: The role of family variables. J. Marriage Fam. 61: 85-99.

Miller, K., Forehand, R., and Kotchick, B. (2000). Adolescent sexual behavior in two ethnic minority groups: A multi-system perspective. Adolescence 35: 313-333.

Moore, K., Peterson, J., and Furstenberg, F. (1986). Paternal attitudes and the occurrence of early sexual activity. J. Marriage Fam. 48 : 777-782.

Mott, F., Fondell, M., Paul, N., Kowaleski-Jones, L., and Menaghan, E. (1996). The determinants of first sex by age 14 in a high-risk adolescent population. Fam. Plann. Perspect. 28: 13-18.

Murphy, J., and Boggess, S. (1998). Increased condom use among teenage males, 1988-1995: The role of attitudes. Fam. Plann. Perspect. 30: 276-303.

Newcomb, M., Huba, G., and Bentler, P. (1986). Determinants of sexual and dating behaviors among adolescents. J. Pers. Soc. Psychol. 50: $428-438$. 
Newcomber, S., and Udry, J. R. (1985). Parent-child communication and adolescent sexual behavior. Fam. Plann. Perspect. 17: 169-174.

Norris, A., and Ford, K. (1999). Sexual experiences and condom use of heterosexual low income African American and Hispanic youth practicing relative monogamy, serial monogamy, and non-monogamy. Sex. Transm. Dis. 26: 17-25.

Oliver, M., and Hyde, J. (1993). Gender differences in sexuality: A meta-analysis. Psychol. Bull. 114: 29-51.

Peplau, L. A., Cochran, S. D., and Mays, V. M. (1997). A national survey of the intimate relationships of African American lesbians, and gay men: A look at commitment, satisfaction, sexual behavior and HIV disease. In Greene, B. (ed.), Ethnic and Cultural Diversity Among Lesbians and Gay Men: Psychological Perspectives on Lesbian and Gay Issues. Sage, Thousand Oaks, CA, pp. 11-38.

Poitras, M., and Lavoie, F. (1995). A study of the prevalence of sexual coercion in adolescent heterosexual dating relationships in a Quebec sample. Violence Vict. 10: 299-313.

Porter, C., Oakley, D., Ronis, D., and Neal, W. (1996). Pathways of influence on fifth and eighth graders'reports about having had sexual intercourse. Res. Nurs. Health 19: 193-204.

Raine, T., Jenkins, R., Aarons, S., Woodward, K., Fairfax, J., El-Khorazaty, M., and Herman, A. (1999). Sociodemographic correlates of virginity in seventh-grade Black and Latino students. J. Adolesc. Health 24: 304-312.

Remez, L. (2000). Oral sex among adolescents: Is it sex or is it abstinence? Fam. Plann. Perspect. 32: 298-304.

Remafedi, G. (1987). Homosexual youth: A challenge to contemporary society. JAMA 258: 221-225.

Rice, F. (1999). The Adolescent: Development, Relationships, and Culture (9th ed.). Allyn and Bacon, Boston, MA

Romer, D., Stanton, B., Galbraith, M., Feigelman, S., Black, M., and Xiaoming, L. (1999). Parental influence on adolescent sexual behavior in high-poverty settings. Arch. Pediatr. Adolesc. Med. 153: $1055-1062$.

Romo, L., Lefkowitz, E., Sigman, M., and Au, T. (2002). A longitudinal study of maternal messages about dating and sexuality and their influence on Latino adolescents. J. Adolesc. Health 31(1): 59-69.

Rosenbaum, E., and Kandell, D. (1990). Early onset of adolescent sexual behavior and drug involvement. J. Marriage Fam. 52: 783-798.

Rucibwa, N., Modeste, N., Mongtomery, S., and Fox, C. (2003). Exploring family factors and sexual behaviors in a group of Black and Hispanic adolescent males. Am. J. Health Behav. 27(1): 63-74.

Sallis, J., and Owen, N. (1997). Ecological models. In Glanz, K., Lewis, F., and Rimer, B. (eds.), Health Behavior and Health Education (2nd ed.). Jossey-Bass, San Francisco.

Sampson, R. (1992). Family management and child development: Insights from social disorganization theory. In McCord, J. (ed.), Advances in Criminological Theory (Vol. 3). Transaction, New York.

Santelli, J., Brener, N., Lowry, R., Bhatt, A., and Zabin, L. (1998). Multiple sexual partners among U.S. adolescents and young adults. Fam. Plann. Perspect. 30: 271-275.

Santelli, J., Lindberg, L., Abma, J., McNeeley, C., and Resnick, M. (2000). Adolescent sexual behavior: Estimates and trends from four nationally representative surveys. Fam. Plann. Perspect. 32: 156.

Savin-Williams, R. C. (1996). Dating and romantic relationships among gay, lesbian, and bisexual youths. In The Lives of Lesbians, Gays, and Bisexuals: Children to Adults. Harcourt Brace, pp. 166-180.

Savin-Williams, R. C. (1998). And Then I Became Gay: Young Men's Stories. Routledge, New York.

Schuster, M., Bell, R., Berry, S., and Kanouse, D. (1998). Impact of a high school availability program on sexual attitudes and behavior. Fam. Plann. Perspect. 30: 67-72, 88.

Sieving, R., McNeely, C., and Blum, W. (2000). Maternal expectations, mother-child connectedness, and adolescent sexual debut. Arch. Pediatr. Adolesc. Med. 154: 809-819.

Small, S., and Luster, T. (1994). Adolescent sexual activity: An ecological risk factor approach. J. Marriage Fam. 56: 181-192.
Smith, C. (1997). Factors associated with early sexual activity among urban adolescents. Soc. Work 42: 334-346.

Smith, E., and Udry, J. R. (1985). Coital and non-coital sexual behaviors of white and black adolescents. Am. J. Public Health 75: $1200-1203$.

Social Forces. (1994). Explaining race and gender differences in adolescent sexual behavior. Soc. Forces 3: 1-13.

Sonenstein, F., Ku, L., Lindberg, L., Turner, C., and Pleck, J. (1998). Changes in sexual behavior and condom use among teenaged males: 1988 to 1995. Am. J. Public Health 88: 956-959.

Spencer, J., Zimet, G., Aslsma, M., and Orr, D. (2002). Self-esteem as a predictor of initiation of coitus in early adolescents. Pediatrics 109(4): 581-584

Spencer, M. (1991). Minority development of identity. In Lerner, R., Peterson, A., and Brooks-Genn (eds.), Encyclopedia of Adolescence. Garland, New York.

Stein, A. (1989). Three models of sexuality: Identities and practices. Sociol. Theory 7: 1-13.

Tollman, D., and Diamond, L. (2000). Desegregating sexuality research: Cultural and biological perspectives and gender and desire. Аппи. Rev. Sex Res. 12: 33-74.

Tubman, J., Windle, M., and Windle, R. (1996a). Cumulative sexual intercourse patterns among middle adolescents: Promotion behavior precursors and concurrent health risk behaviors. J. Adolesc. Health 18: $182-191$

Tubman, J., Windle, M., and Windle, R. (1996b). The onset and crosstemporal patterning of sexual intercourse in middle adolescence: Prospective relations with behavioral and emotional problems. Child Dev. 67: 327-343.

Tschann, J., Adler, N., Millstein, S., Gurvey, J., and Ellen, J. (2002). Relative power between sexual partners and condom use among adolescents. $J$. Adolesc. Health 31(1): 17-25.

Udry, J. R. (1988). Biological predispositions and social control in adolescent sexual behavior. Am. Sociol. Rev. 53: 709-722.

Udry, J. R. (2000). Biological limits of gender construction. Am. Sociol. Rev. 65: 443-457.

Udry, J. R., and Billy, J. (1987). Initiation of coitus in early adolescence. Am. Sociol. Rev. 52: 841-855.

Upchurch, D., Aneshensel, C., Sucoff, C., and Levy-Storms, L. (1999). Neighborhood and family contexts of adolescent sexual activity. J. Marriage Fam. 61: 920-933.

Upchurch, D., Levy-Storms, L., Sucoff, C., and Anashensel, C. (1998). Gender and ethnic differences in the timing of first sexual intercourse. Fam. Plann. Perspect. 32: 121-127.

Valois, R. F., Kammermann, S. K., and Drane, J. (1997). Number of sexual intercourse partners and associated risk behaviors among public high school adolescents. J. Sex Educ. Ther. 22: 13-22.

Valois, R. F., Oeltmann, J. E., Hussey, J. R., and Waller, J. (1999). Relationship between number of sexual intercourse partners and selected health risk behaviors among public high school adolescents. J. Adolesc. Health 25: 328-335.

Villarruel, A., and Rodriguez, D. (2003). Beyond stereotypes: Promoting safer sex behaviors among Latino adolescents. J. Obstet. Gynecol. Neonatal Nurs. 32: 258-263.

Walter, H., Vaughn, R., Gladis, M., Ragin, D., Kasen, S., and Cohall, A. (1992). Factors associated with AIDS risk behaviors among high school students in an AIDS epicenter. Am. J. Public Health 82: 528-532.

Whitaker, D., Miller, K., and Clark, L. (2000). Reconceptualizing adolescent sexual behavior: Beyond did they or didn't they? Fam. Plann. Perspect. 32: 111-117.

Whitbeck, L. (1999). Early adolescent sexual activity: A developmental study. J. Marriage Fam. 61: 934-947.

Zall-Crawford, B. (2001). A Study of Parental Influence on Adolescent Males' Sexual Attitudes and Behaviors. Dissertation Abstracts International: Section B: The Sciences \& Engineering, Vol. 62, p. 2118. 